\title{
User's Guide for TWOHEX: A Code Package for Two-Dimensional, Neutral-Particle Transport in Equilateral Triangular Meshes
}

\author{
Wallace F. Walters \\ Forrest W. Brinkley \\ Duane R. Marr
}

\section{DISCLAIMER}

\begin{abstract}
This report was prepared as an account of work sponsored by an agency of the United States
Government. Neither the United States Government employees, makes any warranty States Government nor any agency thereof, nor any of their oility for the accuracy, completeness, or implied, or assumes any legal liability or responsi-
\end{abstract} .. - acuracy, completeness, or usefulness of any information, apparatus, product, or 
ABSTRACT . . . . . . . . . . . . . . . . . v

I. INTRODUCTION . . . . . . . . . . . . . . . . . . . . . I-1

II TWDHEX OVERVIEW . . . . . . . . . . . . . . . II -
A. Progamming Practices and Standaras. . . . I I-1
B. TWOHEX Code Package Structure. . . . . . II-1
C. INPUT Module. . . . . . . . . . . . . II-2
D. SOLVER module............... . . II-3
E. EDIT Module................ . . II-3

III. FREE FIELD INPUt . . . . . . . . . . . . III-1

IV. TWOHEX INPUT SPECIFICATIONS ......... . . $\ldots-1$

A. Input Dverview. . . . . . . . . . . . . IV-1

B. MINI-MANUAL . . . . . . . . . . . I $1 \%-3$

C. Full Input Details. . . . . . . . . . IV-6

Title Card Deqails. . . . . . . . . . IV-7

Block I: Controls and Dimensions. . . IV-B

Block II: Geometry Details........ IV-9

Block III: Nuclear Data Detalls.... IV-10

Block IV: Mixing Detalls....... IV-12

Block V: SOLVER Details........ . IV-14

Block VI: EDIT Input Detalls...... IV-19

APPENDIX A: Interface File Specifications. . . 4- 1

APPENDIX B: Sample Input. . . . . . . . . . B-1

APPENDIX $C$ : CCF ACCess and Execution....... . C-1

REFERENCES . . . . . . . . . . . . . . . . . . R-1 
USER'S GUIDE FOR TWOHEX:

A CODE PACKAGE FOR TWO-OIMENSIONAL, NEUTRAL-PARTICLE TRANSPORT

IN EOUILATERAL TRIANGULAR MESHES

oy

Wallaze F. Walters. Forrest W. Brinkley. and Duane R. Marr

ABSTRACT

1. Program identification: TWOHEX

2. Computers for which Program is designed: CRAY-IS, CRAY-XMP

3. Function: TWOHEX solves the two-dimensional multigroup transport equation on an equilateral triangular mesh in the $x, y$ plane. Both regular and adjoint, inhomogeneous ( $f$ ixed source) and homogeneous problems are solved. Three problem domains are treated by TWOHEX. The "whole core" domain is a 60 degree parallelogram with vacuum boundary conditions on each face. The "third core" domain is a 120 degree parallelogram with two vacuum and two rotational boundary conditions. The "sixth core" domain is a 60 degree parallelogram with two vacuum and two rotational boundary conditions. General anisotropic scattering is al iowed and an anisotropic inhomogeneous source may be input as cell averages.

4. Method of Solution: TwOHEX numerically solves the two-dimensional, multigroup form of the neutral-particle, steady-state Boltzmann transport equation. The discrete-ordinates form of approximation is useci for treating the angular variation of the particle distribution and a linear characteristic/nodal scheme is used for spatial discretization. There is no negative flux fixup since few if any negat ive $f$ luxes are generated by this numerical scheme. A standard inner (within-group) tteration, outer (energygroup-dependent source) iterat ir... technique is used. Both inner and outer iterations are accelelated using the Chebyshev acceleration method.

5. Restrictions: The code is thoroughly variably dimensioned with a flexible, sophisticated data management and transfer capability. The code is designed for $z$ three-level hierarchy of data storage: a small, fast core central memory (SCM), a fast-access peripheral large core memory (LCM), and random-access periphera) storage. (For computing systems based on a two-level hierarchy of data storage - a large fast core and random-access peripheral storage - a portion of fast core is designated as a simulated LCM to mimic the three-level hierarchy). With the exception of the SOLVER module, random-access storage is used if LCM (ur simulated LCM) storage requirements are exceeded The SOLVER module does not make use of random-access storage. Normally, an SCM of about 25000 words of storage and an LCM (or simulated LCM) of a few hundred thousand words or less storage are sufficient to eliminate the need for using random access storage. 
6. Running Time: Running time is directly relatied to problem size and to central processoi and data transfer speeds. On a CRAY-15. a four group calculation of the elgenvalue of a midplarie whole core model of the fast Test Reactor ( $\left.F^{-7}\right)$ took 45 seconds. The calculation used transport corrected Po cross sect Ins. an S4 angular qu: idrature with 12 angles per hemisphere, and a 60 by 30 spatial mesh (six triangles per subassembly).

7. Unusual eeatures of the Program: The TwOHEX code package is modulariy structured in a form that separates the input and the output (edit) functions from the main calculational (solver) section of the code. The code makes use of binary. sequential data files. Called interface files, to transmit data between modules and subinodules. Standard interface files whose specifications have been defined by the Reactor Physies Committee on Computer Code Coordination are accepted, used. and created by the code. ONEDAN ${ }^{\top}$ style free-field card-image input capadility is provided for the user. The code provides the user with cor:siderable flexibility in using both card-image or sequential file input and also in controling the execution of both modules arid submodules.

8. Progmamming Languages: The program is written in standard FORTRAN-77 language.

9. MaChine Requirements. Six Input/Output units and up to 14 interface units are required. The number of interface units needed is problem dependent. Typically, 10 such units are Lised. Memory requirements are problem dependent. Dut for most problems a fe' riundred thousand words are adequate. Random access auxiliary storage may occasionally be required if LCM (or simulated LCM) storage is insufficient for the problem being executed.

10. Material Available: Source deck (abolt 45000 cara images). sample problems, this manual, and the ONEDANT manual(Ref. 2 ). 


\section{INTRODUCTION}

The TWOHEX code package is a modjlar computer orogram oesigned to solve the two-dimenstonal. time-indepe ident, multigroup dis'-reteordinates form of the Boltzmann transport equation. TwOHEX uses the same modular construction as the DNEDANT code. This modular construction separates the input processing. the transport equation solving. and the postorocessing. or edit functions, into distinct. independently executable code modules, the INPUT, SOLVER, and EDIT modules, respectively. These modules are connected to one another solely by means of binary iriterface files. The INPUT module and, to a lesser degree, the EDIT module are general in nature and are designed to be standardized modules. Witn these modules. different new production codes can be created simply $D_{y}$ developing different SOLVER modules that can be "plugged in" to the standardized INPUT and EDIT modules.

The TWOHEX code is 5 imply the ONEDANT package with the one-dimensiona! SOLVER module replaced with a two-dimensional SOLVER module. As such. large portions of the ONEDANT manual apply to TWOHEX as well. This TwOHEX user's guide follows the ONEDANT manual form ever: to the point of having the same chapter and section numbering. Thus. chapter IV. section C contains the full input specifications. in either manual Frequently, for sections which apply equally to both codes, a ve. $y$ brief discussion will be given here and the user will be referred to the ONEDANT manual for more details. This is oniy done for sections. that are of background interest or for sections that go into great detail. Once the general scheme of things is known, the user should only very infrequently need to access the ONEDANT manual. Thus, this TWOHEX user's guide is intended to be complete in the sense that all trie input arrays are described along with evervthing else needed to make most runs.

Some of the major features included in the TWOHEX pack age are

(1) a ONEDANT type, free-fielo forma: card-image input capability designed with the user in mind.

(2) highly soph:sticated. 5tandardized, data- and file-managemen: techniques as definid and developed by the Committee on Computer Coordination (:CCC) and described in Ref. 1: Do in sequential file and raridom-access file handling techriques are used,

(3) the use of standard Chebychev accelerat on of both the inneand outer iterations.

(4) direct (forward) or adjoine calculational capability.

(5) geometry domains for sixth core. third core and whole core including appropriate boundary conditions.

(6) arbitrary anisotropic scattering order.

(7) inrumogeneous ( $f$ ixed) source or k-effective calculation iptions.

(8) nodal/characteristic transport method for solution o: the transport equation.

(9) user flexibility in using either card-image or sequential file input.

(10) user flexibility in controlling the execution of both modules and submodules, and

(11) ext. . sive, user-oriented error diagnostics. 
TWOHEX is a large, very flexible code package. Great effort has been devoted to making the code hignly user-oriented. Simple problems can be easily run and many of the code options can be ignored by the casual user. At the same time numerous options for selective and sophisticated execitions are available to the more advanced user. In all cases redundaricy of input has been minimized, and default values for many input parameters are provided. The code is designed to be "intelligent" and to do much of the work for the user. The input is designed to be meaningful. easily understood, easily verified, and easy to change. The printed output is well documented with liberal use of descriptive comments and headings. In short. TwOHEX was designed to be fun to use.

Chapter Il of this manual provides the user with a brief overview of the code package. Included are sections on programming practices and standards, code package structure. and functional descriptions of the three principal modules comprising the package. All this information applies to ONEDANT as well, and more complete discussions of each section can be found in the ONEDANT manual.

Chapter III presents the free-field format rules for the card-image input. The more esoteric forms of input inat Doth ONEDANT and TWOHEX support are not described here and the user is referred to the ONEDANT manual for a discussion of those items.

Chapter IV provides the card-image input specifications for TwOHEX. First is given an overview of the specification of input including descriptive examples. Next is a "mini-manual" on which are listed all the available input arrays arranged by input block. This mini-manual is very useful to the user in organizing his input. For the more experienced user, the mini-manual is frequently all that is needed for him to specify his input. Fo'lowing the mini-manual is a moderately detailed description of all the input parameters and arrays. TWOHEY.

Chapters II. III, and IV should be read by ali first-itime users of

Chapters V, VII, VIII, and IX of the CNEDANT manual largeiy apply to TWOHEX as well, and are not included in this guide. Those chaptels are briefly described below.

Chapter VII is devoted to details related to th. EDIT module of the code. Both input and execution control options for this module are described in detail. This chapter supplements informat:on pertaining to the EDIT modu'e provided in Chapter IV.

Ir. Chapter VIII is a discussion of some of the more sophisticated options available to the idvanced user for controlling the execution of modules and submodules in ONEDANT.

Clapter IX presents a discussion of the error diagnosticz available in ONEDANT. Several examples of errors and the resulting error messages are provided for the user. 
The information in four appendices is germane to the running of TWOHEX. Appendix a the ONEDANT manual provides the file descriptions for the code dependent. Dinary. sequentiol interface files generated by and used in the ONEDANT code package. As these are identical to the files used by TwOHEX. "hat appendix is not included here. File descriptions for the CCCC standard interface files are also not

provided. Dut can be found in Ref. 1. Appendices $B$ and $C$ are found in this user's guide. Appendix B provides a sample TWOHEX problem for the user. Dpendix $C$ shows how to access the code at Los Alamos. 
The TWOHEX code package is a computer program designed to solve the two-dimenstonal, mult group, discrete-ordinates form of the neutral particle Boltzmann trisneport equation. It was developed as a modular code package cons.sti.ig of threg modules: an INPUT module, a SOLVER module, anu an EDIT module.

In this chapter is provided a brief discussion of the general programming practices and standards used in the code package. a description of the code structure, and overviews of the three modules comprising the package.

A. Programming Practices and Standards

In general, the programming standards and practices recommended in Ref. 1 from the Committee on Computer Code Coordination (CCCC) have Deen followed throughout the development of TwOHEX. By following these practices and standards, problems associated with exporting and implementing the code in different computing environments and at different computing instaliations are mintmized. The programming practices and standards are also described in more detail in the ONEDANT manual (Ref. 2) and the user is referred thereto.

\section{B. TWOHEג Code Package Structure}

The TWOHEX code package consists of three major functionally independent modules: an INPUT module, a SOLVER module, and an EDIT moduie. These modules are linked by means of binary interface files. The INPUT module processes any and all input specifications and data ind, if requirec, generates the binary files for use by the SDLVER and/or EDIT modules. The SOLVER module performs the transport calculatior, and generates flux files for use by the EDIT module. The SOLVER inodule also generates other interface files for use by other codes or for subsequent calcuiations by the SOLVER module. The EDIT modulo performs cross-section and response function edits using the flux ifles from the SDLVER module.

The interface files accepted, used, and generated by the modiles are described ir, detail in the ONEDANT manual. Also shown there is the relationship of each of the files to each of the modules. finere it is used, where it is written, and so forth. That detail is not repeateo here. The fact that interface files are used at all is not generally useful to the user unless he is making his runs in plecewise fashion.

A three-level ove-lay structure is used in TwOHEX for 1 molementing the modules. Such a structure involves the use of a main overlay together with primary and secondary overlays.

The main (or 0.0 ) overlay contains the main program routine, which controls the calling of the prlmary overlays, together with those service subroutines used by more than one primary overlay.

The first overlay constitutes the INPUT module. It is structured into the first primary (or 1.0 ) overlay plus twelve secondary overlays, each of which performs a unique function, usually the reading of a Block of input and the writing of ane of the interface files. The INPUT module is also constructed in moduiar form and indeed may even be executed niecewise, if so desired. This module is identical to the INPUT modile of ONEDANT

The second overlay constitutes the SOLVER, or calculational. module. It consists of the second primary (or 2,0 ) over lay plus nine secondary overlays, each performing a part of the flux calculation. 
The third overlay is the EDIT module. It currently consists of the third primary', or $(3,0)$, overlay plus a single secondary overlay. This module is identical to the EDIT module of ONEDANT.

Normally all three of these modules will be executed in a given run a)though it is possible to run them individually given the necessary interface files. For a complete discussion of this latter technique. see the ONEDAINT manual (Rer. 2 ).

A fourth overlay is also used in TWOHEX. This overlay contains only the fourth primary. or $(4,0)$, overlay with two subroutines. inis fourth overlay provides highlights of the just-executed run as an aid to the user. Tnese highlights are a printed summary of some of the pertiment facts, options, and decisions encountered during tine run along with storage and run time information. This overlay is not considered to be a module in the sense of the first three overlays.

c. INPUT module

C................

The INPUT module performs the necessary activities for processing al 1 input data required for the execution of the SOLVER and/or EDIT modules. These activities include the reading of input data and the creation of binary interface files. The latter activity may require a certain degree of data processing. Each of these activities is discussed below.

In performing the reading-of-input data activity, the INPUT module accepts standard interface files (binary), code-dependent binary interface files, or card-images for its input. Input data can be provided in several different forms and many combinations of forms to provide a great deal of flexibility to the user. Chapter IV of this manual and Chapters IV, V. VI, and VII of the ONEDANT manual provide specific information and further details on the specification of tr.a input data.

The second major activity in the INPUT module is the creation of binary interface files containing all input data. These files are subsequently used as the sole means of transmitting data to either the SOLVER or EDIT inodules. The files emerging from the INPUT module take the form of either CCCC standard interface files or code-dependent interface files. In this file creation activity the INPUT module is called on to naiform several tyes of tasks. As an example. the only form in whicn geometry related information emerges from the INPUT module is in the form uf a GEDDST standard interface binary file. If a user supplies geometiy related input by means of card-image input. a particular submodule of the INPUT module reads this input. translates the data into a GEDDST compat ible form, and creates he resulting GEODST file. On the o:her hand, if the geometry related friformation is supplied by the user through an already existing GEODST file, the INPUT module is required to do nothing. In either case, the GEDDST file will be avuilable for the SOLVER module to use when doing the flux calculation. A second, more complex example of the function of the INPUT module involves the mixing of isotopes, or nuclides, to create Materials which are subsequently assigned to physical regions in the problem (called Zones) to def ine the macroscopic cross-section data for the Zones. For this example it will be assumed that the user selects card-image inpu: as the form for the INPUT module. First, the isotope mixing specifications appropriate for the desired Materiais are input $v i a$ card-image. The INPUT module reads this data, translates the datz. and creates the two standard interface files NDXSRF and ZNATDN. Assuming next that the isotope cross sections are provicied by the user as a card-image library, another submodule of the IWPUT module reads this 1 ibrary (in tsotope ordered form) and also reads the just created NDXSRF and ZNATDN files. The mixing specifications provided by the latter files are applied to the isotopic cross-section data to generate Material cross sections: those mixed cross sections are then sorted into group order and written to the MACRXS code-dependent binary interface 
fi'e. (A group ordered file nameo SNXEDT for use by the EDIT module is also created at this time but will not be considered in this example.) The MACRXS file becomes the sole source of cross-section data to the SOLVER module if the SOLVER calculation is to be a forward, or regular. calculation. If an adjoint calculation is to be performed by tha SOLVER, yet another submodule of the INPUT module rereads the MACRXS file. performs the adjoint reversais on the cross jections, anj creates the code-dependen: binary file named ADJMAC containing the adjoint reversed ibterial cross sections for use by SOLVER.

\section{SCLVER Module}

The SOLVER module of TWOHEX has the funct on of effecting numerical solutions of the two-dimension, multigroup form of the neutral particle steady-state Boltzmann transport equation. The discrete ordinates approximation is used for treating the anguiar variation of the particle distribution and a nodal/characteristic scheme $s$ used for spatial discretization. This scheme is completely desc. ibed in (Ref. 3 ) as the TLC scheme. A copy of this reference can be obtained by contacting the author of this guide.

In solving the transport equation numerically, an iterative procedure is used. This procedure involves two levels of iteration referred to as inner and outer iterations. The acceleratiou of these iterations is of crucial importance to transport codes in order to reduce the computation time involved. The TwOHEX SOLVER module employs the Chebyshev acceleration method to accelerate the convergence of both the inner and outer iterations. The Chebyshev method as applied to outer iterations is well described in (Ref.4) and (Ref. 5). For inner iterations the method is applied to the self-scatter source instead of the fission source as is done for outer iterations. Copies of the two chebyshev references can be obtained from the author of this guide.

E. EDIT Module

The function of the EDIT Module is to produce the printed edit-output selected by the user. Edit-output refers to information which is obtained from the data contained on one or more interface files but which generally requires manipulating or processing of the data. An example of the edit-output is a microscopic reaction rate distribution. i.e. the product of a microscopic cross section for a particular sotope or nuclide and the flux. In this example, the data from both a cross-section interface file and a scalar flux file are required to be recovered, multiplied, and the product printed.

The EDIT module is an essentialiy free standing module accepting only interface files as input and producing printed output The required input files for execution of the EDIT module are the code-dependent binary interface file EDITIT and the standard interface files RTFLUX (or ATFLUX) and GEODST. Optional inout $f$ les are the standard interface files NDXSRF and ZNATDN and the code-dependfent files SNXEDT and ASGMAT. The code-dependent $f i l e s$ are produced by the INPUT module. 
There are four basic quantities in the free field input used in TWDHEX; they are ARRAY, DATA ITEM. BLDCK, and STRING. Each of these is Jescirioed below.

ARRAY:-

The favored input form (there are several) is one very similar to NAMELIST. Each input array has a unique name. To make ar input to an array. one simply spelis out the array name, appends an equal sign, and follows that with the data items to be entered into the array. For example, input for the $x$ distribution of the volumetric source could look like:

SOURCX $=0 \begin{array}{lllllllllll}0 & 0 & 0 & 2 r & 1.1 & \mathrm{FO}\end{array}$

The above input would enter source values of zero for the first three intervals. 1.1 for the next 2 intervals, an then fill the rest of the IT entries with zero. Note that FIDD-like repeat and fill were used. In general, all the FIDD operators may be used in numeric entry A complete 1 ist of the valid operators is given on the next page in Tat le I I I. 4.

Unlike NAMELIST however, an array name CANNDT use a subscript. The operators A, S, and $E$ may be used for this addressing function.

Data items within an array are separated by blanks or commas. In general. blanks may be used freely throughout except within a data item. within an array name, o- between an array name and its equal sign.

Numeric DATA ITEMS

Numeric data items follow a FORTRAN input convention. For example. all of the collowing are valid entries for the number ten:

$$
\text { 10. } 1.0+1.1 E 1,10.0
$$

If a decimal point is not entered, it is assumed to be after ihe right-most dicit.

Hollerith DATA ITEMS

Hollerith data items follow a FORTRAN variable name convention in that they are composed of up tc six characters, the first of which must Ge alphabetic with the rest alphanumeric. Howaver. special charalters may be included if the data item is surrounded by double quotes.

Operators may NOT be used with Hollerith data items.

B!OCKS

Arrays are entered in groups called blocks. A block consists of one or more arrays (in any order) followed by the single character $T$. Thus $T$ is the block delimiter.

\section{STRINGS}

-......

Arrays may be broken into smaller pieces called strings. Strings are delimited with a semicolon(:). The user should be aware of the arrays that require string input. Strings are frequent ly used to input information by row rather than for the whole 2-d array at once. The code dictates tris, the user has no choice.

Comments

-........

A slash (/) may be used to enter comments in the input stream. After \& slash is read no further processing of that card is done.

For complete detai's of the free field input. the user is referred to the ONEDANT manual, Ref. 2). 
Table III.1 Valid Input Dperators.

-................................

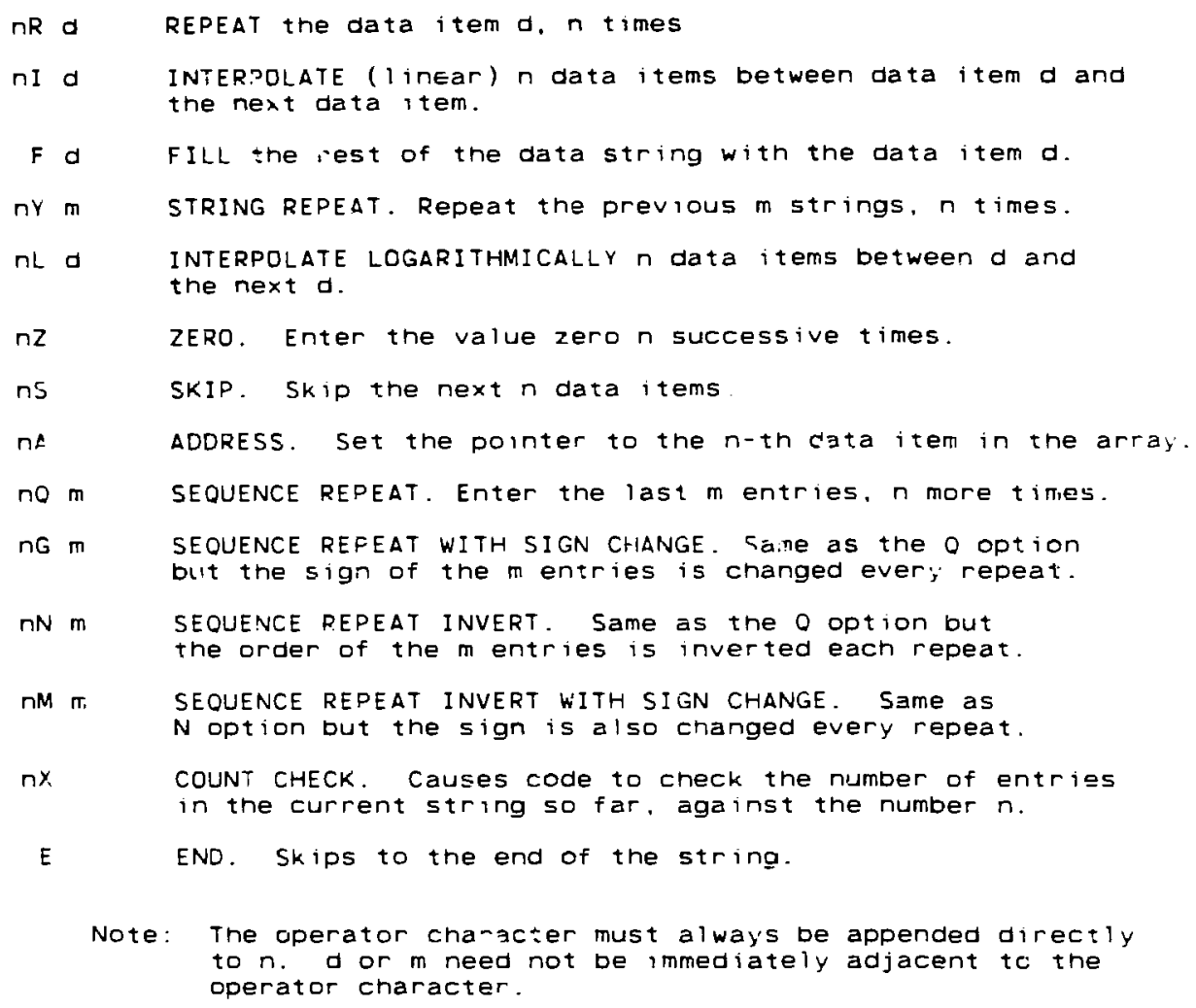


IV. TWOHEX INPUT SPECIFICATIONS

\section{A. Input Overview}

The full TwOHEX input consists of a title card sectiori, followed by $s i x$ blocks of free field input. The title card section is not free field. Any input referred to as a block uses the free field input form.

Block-I consists of basic control and dimensional information that a'lows efficient packing of the array data. This information also al lows checking of the lengths of arrays supplied by interface files.

Slock-Il contains the geometric information.

Block-III consists of the nuclear data specifications.

Block-IV contains mixing information.

Block- $V$ contains the rest of the input needed for specifyirg the fiux ca,cuiztion.

And lastly. Block-Vi contains the edit (i.e. report writing) specisications.

A cross-section library may optionally be placed between Blocks J: I and $: V$, if it is in card image form. TwOHEX supports many i ibrary formats and so the library may or may not be in $?$ ee field format depending upon the jption chosen.

A full infut wrold tmen look like that diagrammed in Figure $: V .1$ on the following page. 


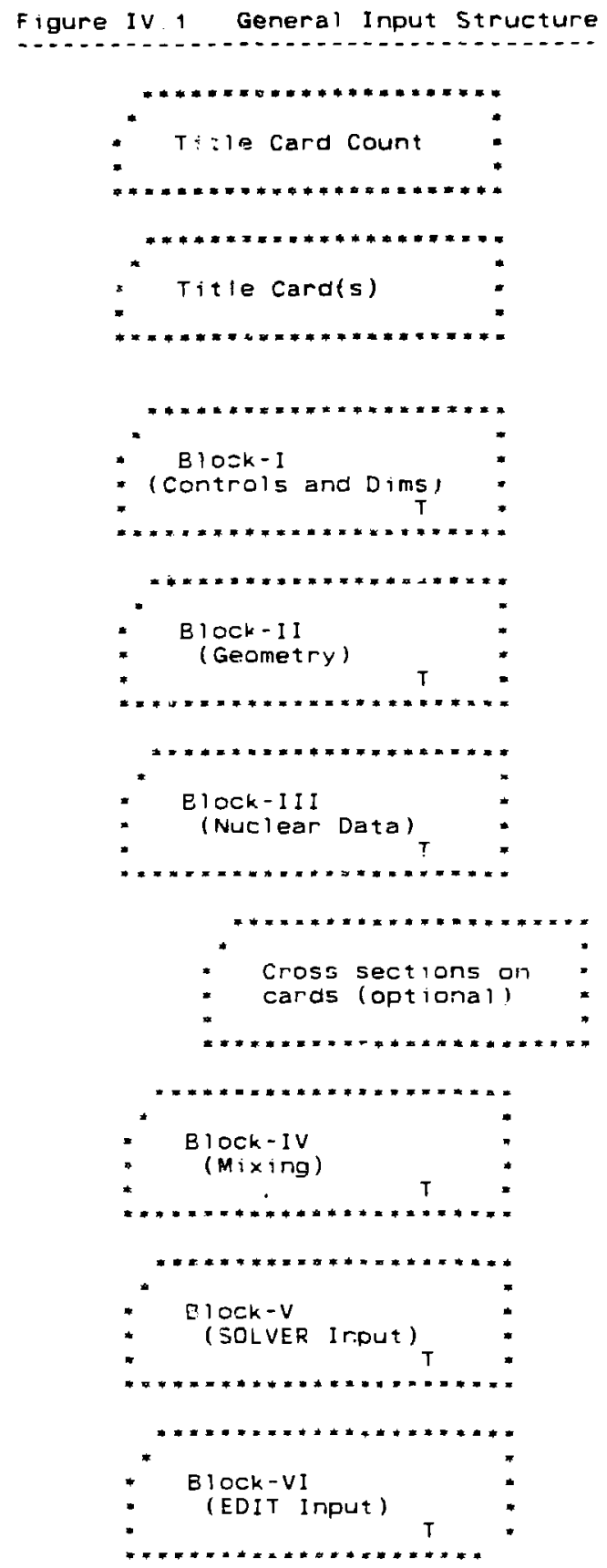


B. MINI - MANUAL

On the following few pages is given a complete list of the input names, expected array sizes. and order within the array. No description of the array contents is given in this MINI-MANLAL as full details are given in later sections and also in the ONEDANT manual. The MINI-MANUAL is intended to serve as a quick reference for the knowledgeable user.

In both the MINI-MANUAL and in the detailed sections which follow, a shorthand form is used to indicate the size and order of the array that the code expects. This information is enclosed in square brackets immediately after the array name. Essential features are:

1. A single entry in the brackets is the array length.

2. No bracliets at all indicates a simple variable 6 i.e. an array $0^{\prime:}$ unit length).

3. A dash (-) in the brackets indicates an arbitrary length.

4. A semicolon (: ) indicates that the irout for that array is expected in strings. To the left of the semicolon is the string length. To the right of the semicolon is the number of strings in the array.

5. If the number of 5 trings is shown as a prociuct, the order is important. The leftmost quantity must be exhausted first. then, the next one to the right is varied. For example, the array name for the fuli spetial source distribution is shown as:

SOURCF [IT:UT * NMO ]

- where IT is the number of $f$ ine meshes in the $x$-direction UT is the number of fine meshes in the $y$-direction, and NMO is the rumber of input source moments. For this array, the first string is composed of the Po source values for each $\times$ mesh point in the first $y$ mesh. The nert string is the Po source values in tine second $y$ mesh. This process is repeated in all $y$ mesties. Then starting again with the first $y$ mesh. the $P_{1}$ source values are given. After all P1 values are given, the P2 values follow. Continue until all NMO moments are specified.

Vcte: Usually. the quantities within brackets will have already been specified in the iriput. Sometimes, however, a quant ity is derived from the array input itself. For instance. in this particular case. NMO is not an input quantity. rather, the code counts the number of strings and then. knowing IT and JT, deduces what NMO must have been. 

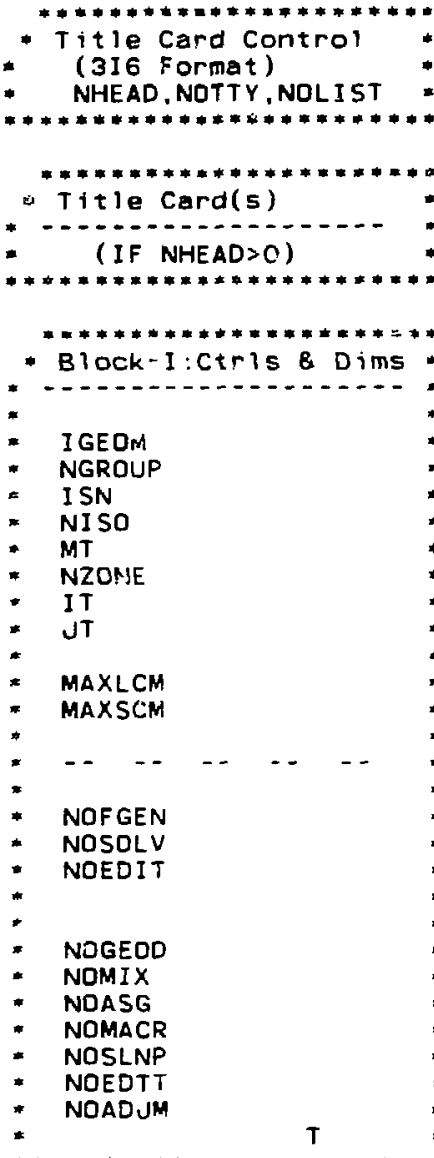

NOF GEN

NOSOLV

NOEOIT

NOGEDD

NOMIX

NOMAC

NOSLNP

NOADJM

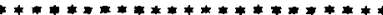

- Elock-II:Geometry

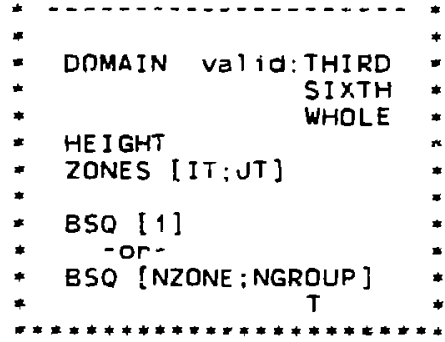

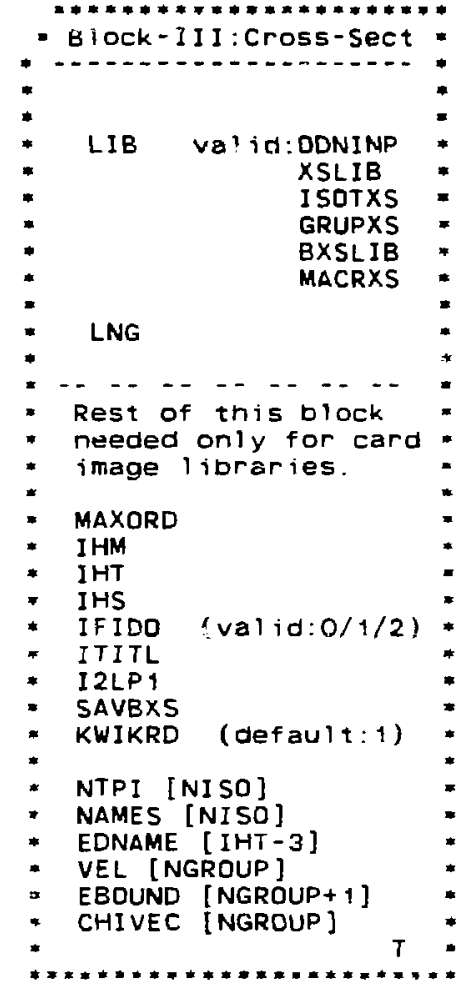

* iff LIB=0ONINP

* insert BCO card-image

- cross sections nere

* * * * *

$* * * * * * *$

* Block-IV: Mixing

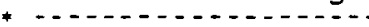

MATLS $[-; M T]$
ASSIGN $[-;$ NZONE $]$
PREMIX [-:-]
MATNAM [MT]
ZONNAM [NZONE] 

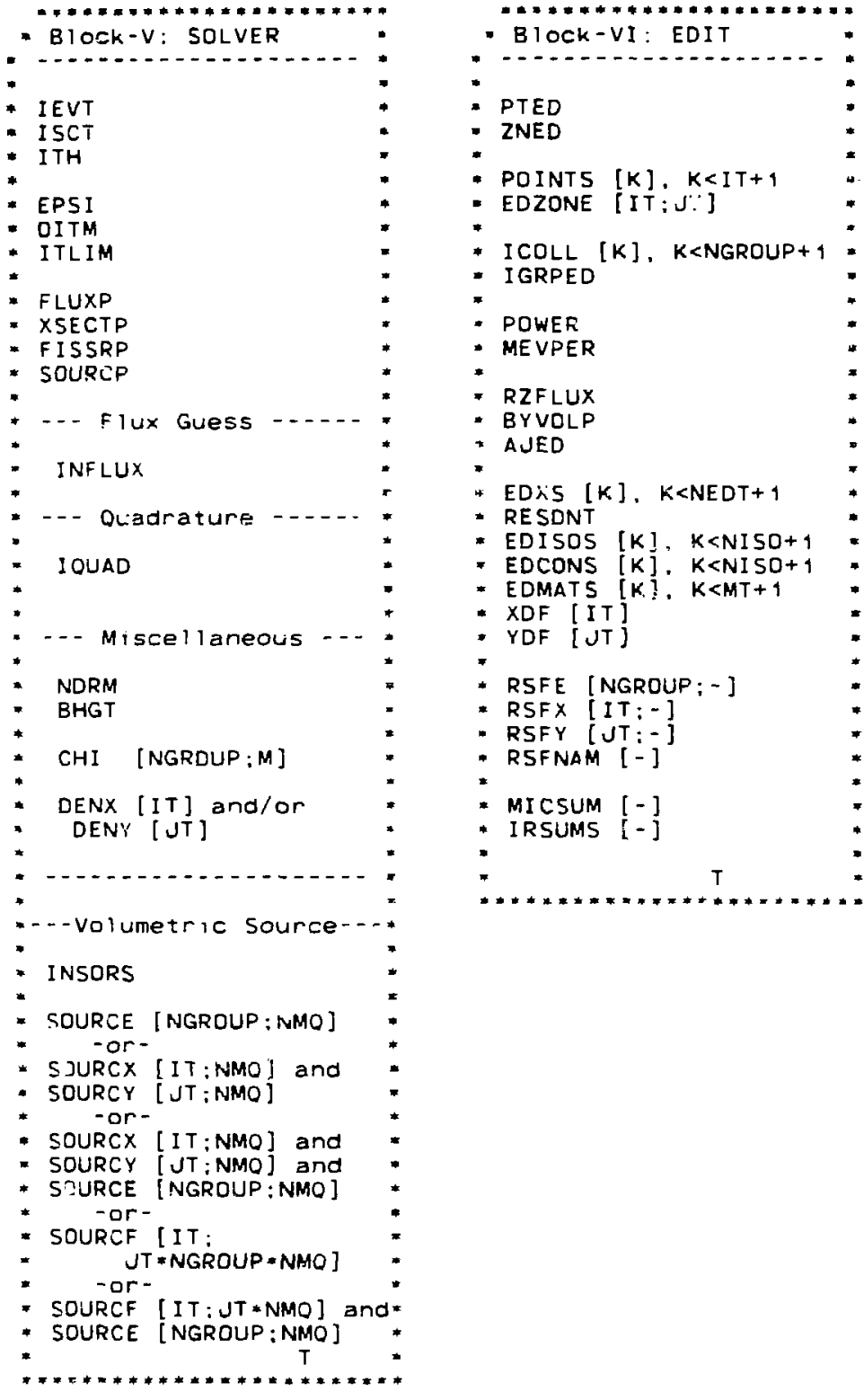
C. Full Input Details

C.

The following pages of this section(i.e. IV.C) give detaris for each of the input arrays. All valid TwnHEX arrays are diseussed in this section in detall complete enough to form the input. However, the beginning user. particularly one unfamiliar with discrete-ordinates codes, may find that he is missing some information of a background nature. For that type of information, the user is referred to the ONEDANT manual (Ref, 2 ).

\section{First, here are a few general instructions:}

1. Ail six of the input blocks are normally lneluded. Block-I is always required but any of the other $f$ ive blocks may be omitted under the proper conditions. The input moduie reads each block in turn and from it generates one or more binary interface files. The interface files drive the SOLVER and EDIT modules. Thus, if the user wants no $E \geq i t s$, the Block-VI input may be omitted. Then with no interface file, the EDIT module will not be executed. Alternatively. if the interface file is available from another source, the corresponding block of input may be onitted. For instance. Block. II describes the geometry. The input module normali, writes this information to the GEODST interface file. If the GEUDST file is available from another source or a previous run, the Block-II input may be omitied.

2. The general theme of the ONEi:ANT input is observed in that arrays that are not needed are not entered. Presence of an array indicates that it should be ustd. Thus, for example, if a density array is entered (e.g. DENX array), the cross section at each mesh point will be modified by the code. No separa:e switch need be set to say that the calculation should be done To eliminate the density modification, simply remove the DENX array from the input.

3. The arrays in general are grouped in the input instructions according to function. Thus. for example, the volumetric source is found on a single page under an appropriate page heading. If one has no volumetric source, one $51 \mathrm{mply} 5 \mathrm{kips}$ to the next page of instructions. There is no need to read furtrer on that page.

4. In an adjoint run. none of the groupw:se input arrays should be inverted. The code will externally identify all groups by the physical group number. not by the calculational gruup number (the calculational group number is in inverse order). Thus. the user interface should be consistently in the physical group order.

5. The use of information within square brackets to indicate the size of arrays and the order within those arrays is the same as described in the introduction to the MINI-MANUAL (previous section).

6. New users reading these instructior.s for the first time and unfamiliar with the TWOHEX input may find it helpful to follow the sample input in Appendix $B$ while reading this section. 


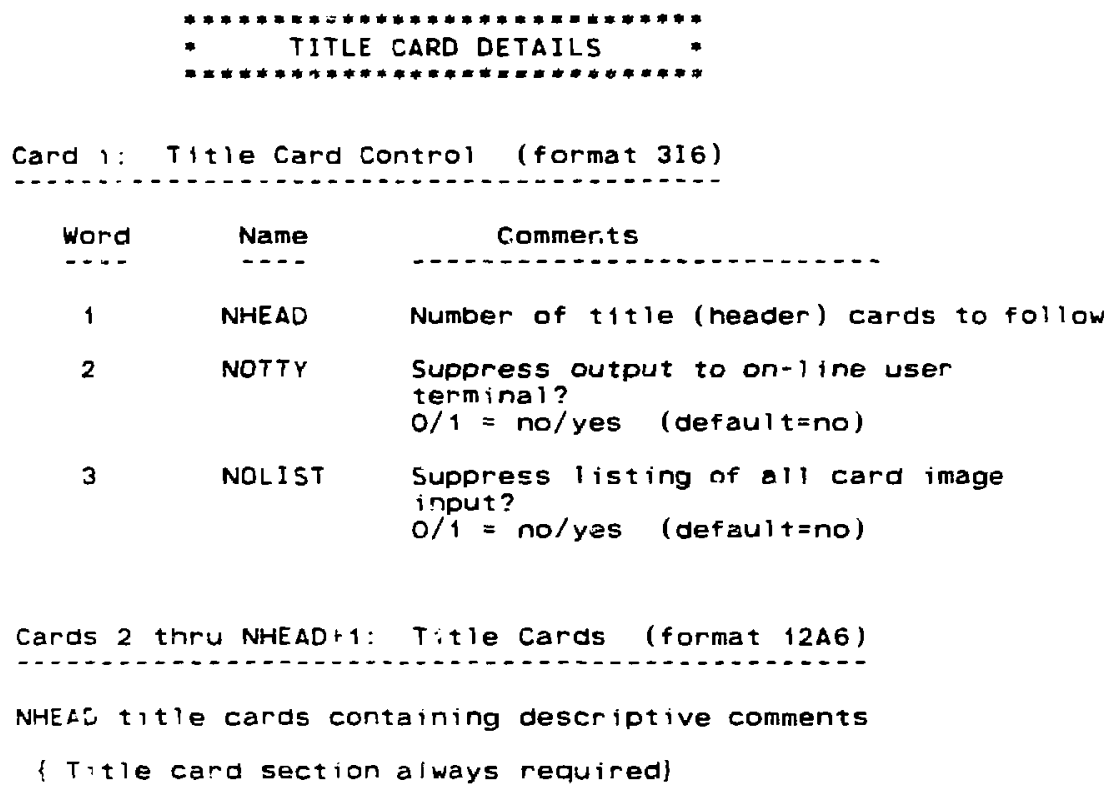




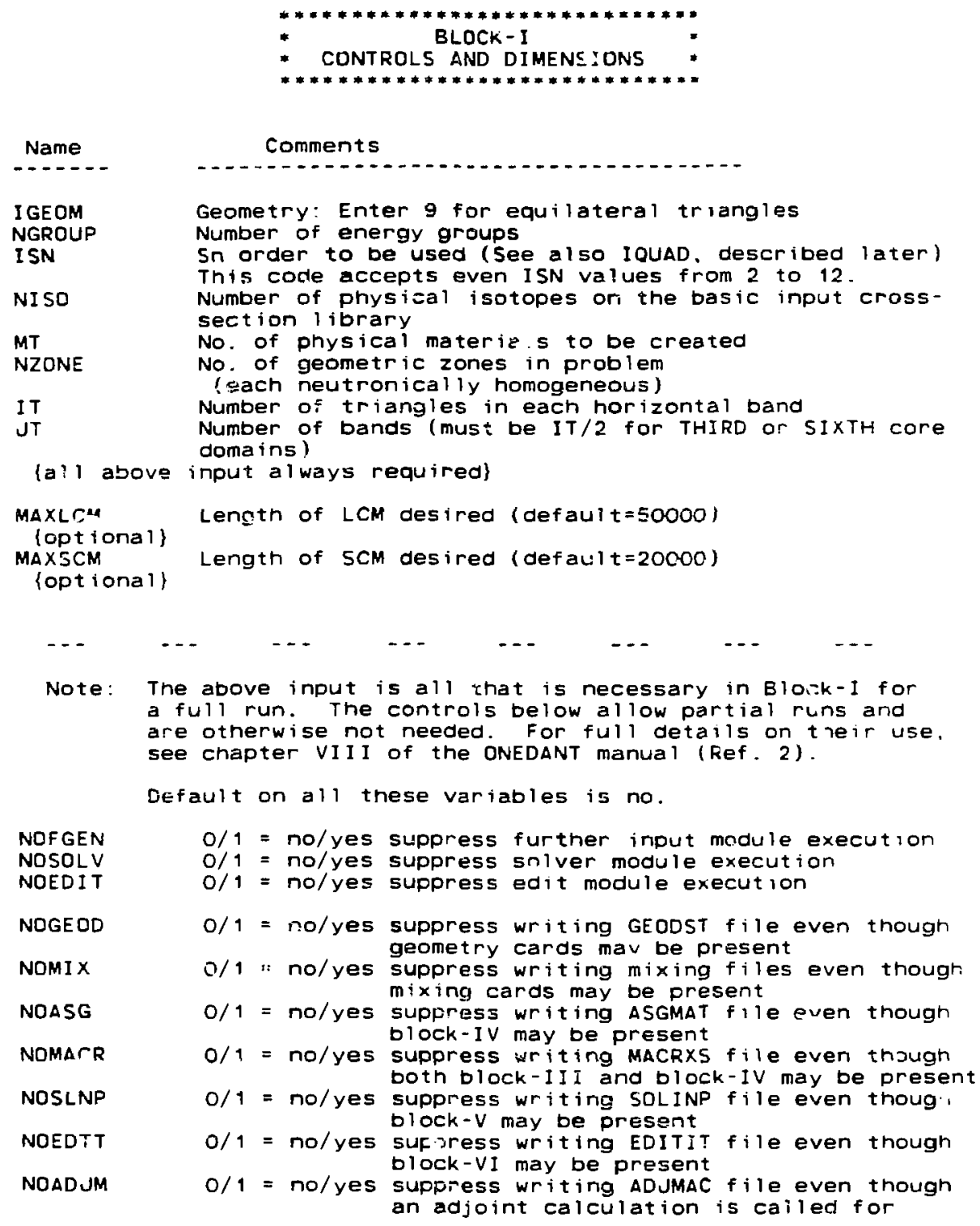




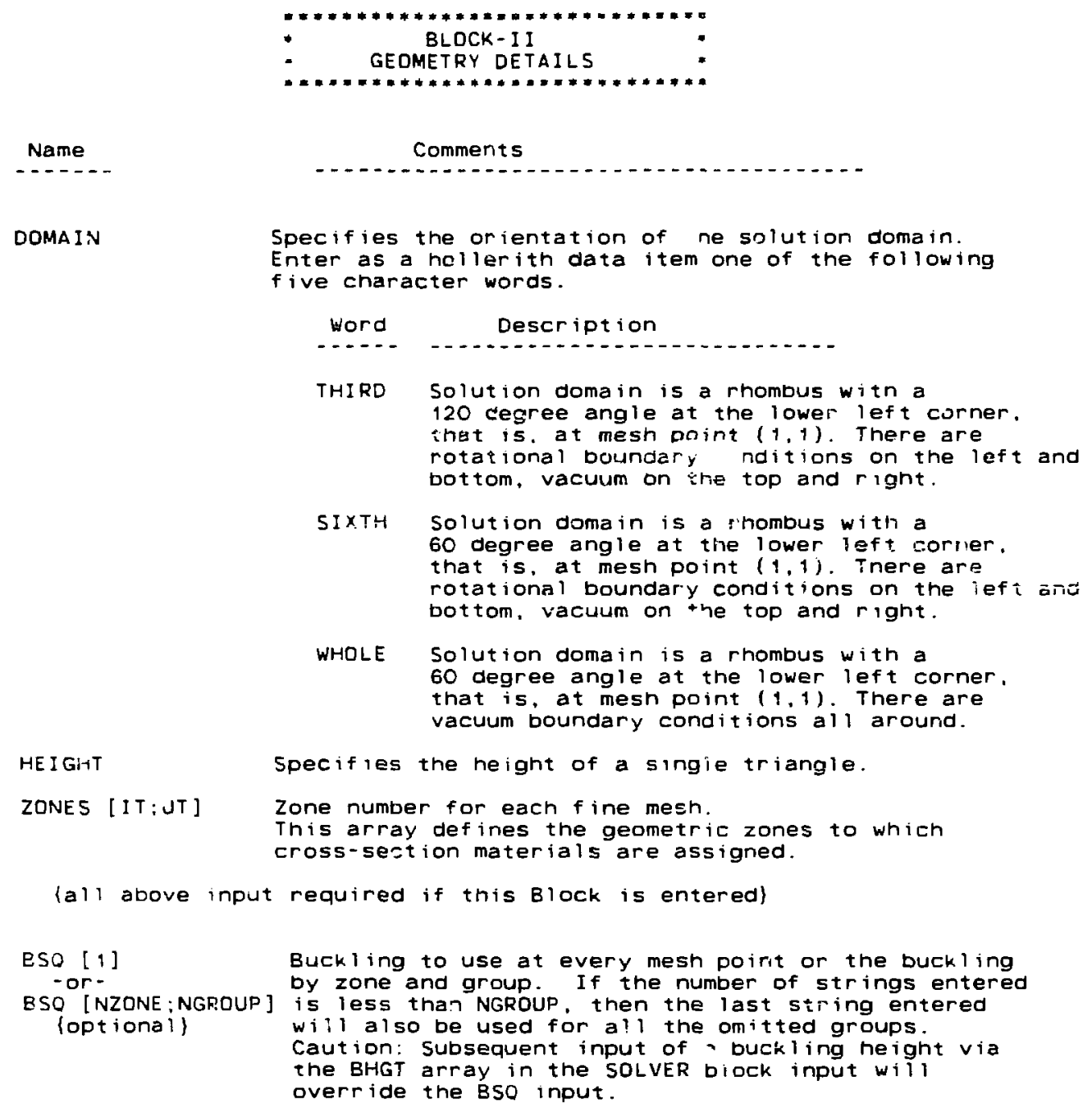

Note: The information entered in this block is writtin to the CCCC standard interface file GEODST. 


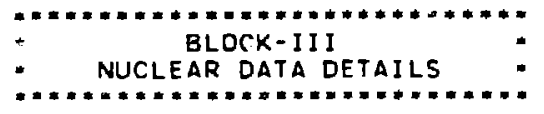

Name

Comments

LIB

\{always

Source of the cross-section data. Enter as a data item one of the following : $:$ character words.

word

- - - -

ISOTX:- C:CC standard isotope ordered binary cross-section file.

XSLIB Card image BCD library supplied in a separate $f$ ile named XSLIB.

ODNINP Card image BCD library follows 3 fter this block of input (after the $T$ of B lock-IYI).

GRUPXS CCCC standard group ondered cross-section file.

BXSLIB Binary form of XSLIB or ODNINP libraries from a previous run. (more efficient)

MACRXS Use existing files named MACR/ $j$ for SOLVER module, SNXEDT for EDIT module. These files were createy in a mrevious run. Under this option any remaining Block-III input and, uniess otherwise specified in Block-I, any PREMIX and MATLS input in BLock-IV will be ignored.

LNG optiona 1$\}$
Number of the last neutron group. Used only to separate neutrons from gammas in the edits.

Notes: 1. The CCCC standard for files ISOTXS and GRUPXS does not a) low the inclusion of the $2 L+1$ term in the higher order scattering cross section. However. if you have a nonstandard file, you may override by setting I 2 LP $1=-1$. TWODANT $W i l$ then accept cross sections containing the $2 L+1$ term.

2. In the convention used in this user's guice. a MACRXS 1 ibrary contains "material" cross sections: all the other libraries contain "isotope" cross sections. 


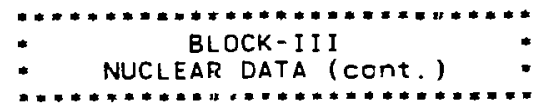

Note: The remaining arrays in block-III ar: used only if the source of cross-section data is XSLIB or CDNINP.

Name

- N...-

MAXORD

I HM

IHT

IHS

IF IDO

$\bullet$

I TITL

I 2 LFI

SAVBXS

KWIKRD

NAMES [NISO]

EDNAME [ IHT-3]

NTPI [NISO]

VEL [NGROUF]

EBDUND [NGROUP+ 1 ]

CHIVEC [NGROUP?

Comments

Highest Legendre order in the scattering tables. Number of rows in a cross-section table. Row number of the total cross secilon.

Row number of the self-scatter cross section. Format of the cross-section library:

$0 / 1 / 2=$ Los Alamos $(6 F, 12) / f i x e d-f i e l d$ FIDO/ free-field FiDO

o/ $1=$ no/yes A title card precedes each taile.

$0 / 1=$ no/yes Higher orjer scattering cross secticns on the library contain the $2 L+1$ term.

$0 / 1=$ no/yes Save the binary form of the card image library XSLIB or ODNINP for use in a subsequent run. Saved on file BXSLIB.

Process fixed-field FIDO-format card-image BCD

library with fast processor at the sacrifice of error checking? $0 / 1=$ no/yes (default=yes)

Hollerith name for each of the input isotopes. Can be used later in mixes. (default names are: I501, I502,...etc. )

Hollerith name for each of the EDIT cross-section positions used in the cross-section edits. These are the positions before the absorption cross section in the cross-section table. (default names are: EDIT1, EDIT2. . . etc. )

Number of Legendre scattering orders for each isotope in the library. (defau $1 t=M A X O R D+1$ ) Speeds for each group. Needed only for alpha calcs. Energy group boundaries. Presently unused. Chi vector (fission fraction born into each group). Used for every isotope. Can be overridden by zone dependent $\mathrm{CHI}$ input in Block-V.

Card image BCD libraries may be entered in one of the three forms indicated in the IFIDO input. All three forms share the following features: Cross sections are entered in a table optionally preceded by a titie card. A table consists of IHM=NGROUP entries, so different Legendre orders are in different tables. Order within group $G$ is as follows:

.. ABS, NU-SIGF, TOTAL,...,Gtog, G-1tog, G-2tog, etc.

$\therefore$ the Los Alamos format, the table is -ntered with a standard FORT: +N 6E 12 format.

In the fixed field fIDO format, entries are made in $s i x$ twe? ve-column fields. Each twelve-column field is divided into three subfields, a two-column numeric field, a one-column character field. and a $n$ ine-column numeric field. See a DOT or ANISN manual (Refs. 6 and,') for details if you are not familiar with this input. The last field in a table must have the character $T$ in the character position. No array ident if ier should be used.

In the free field FIDO form, entries do not have to be in designated columns. Rather, the rules specified in the previous FREE FIELD INPUT BRIEFING apply. Each tabie in this form is a 1 so terminated with the character $T$. No array identifier (i.e. array name with appended equals sign) should be used. 


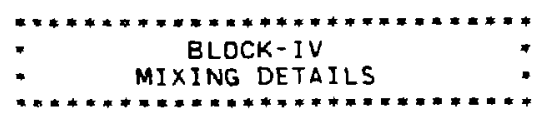

Input to this block is unchanged from that shown in the ONEDANT manual. However, a short summary of the two main mixing arrays is included here for quick reference. Normally, these two irrays are required and, in most problems, would be the only arrays in this block.

The key entities used in specifying the cross-section spatial distribution ire coarse mesh. zone, isotope, and materi 1.

The basic geometry of the problem is defired with the coarse meshes specified in Block-II. The geometric areas called zones are also defined there using the ZONES array: The ZONES irr-y designates which coarse meshes are contained in each zone.

Here in Block-IV, we mix cross sections and assign them to the zones created above The cross sections found on the input librarv belong. Dy definition. to isotopes. nc matter what their true nature. These isotopes may then be mixed to form materials. Using the MATLS= array. Materials are then assigned to zones using the ASSIGN= arriy.

ine general form of a MATLS mix instruction is shown below:

MATLS $=\operatorname{mat} 1$ comp 1 den $1, \operatorname{comp} 2$ den2, ...etc... ;

where - mat 1 is the hollerith name of the first material and comp 1 . comp2, and so on are the hollerith names of its components which have densities of, respectively, den1, den2, and so on. Additional materials may be defined in subsequent strings. Each string may contain as many components as necessary (actual

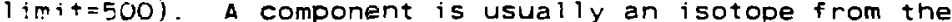
library. but may al so be a temporary material created by the PREMIX = array. The form of the PREMIX = array is identical to that of the MATLS = array. The difference in treatment is that the temporary materials created by PREMIX = exist only long enough to complete the mixing: they are not avaliable for assignment to geometric zones, nor are they available for use in meterial edits.

Short form: MATLS= ISOS

This form specifies that isotope number 1 is to be used for material number 1 , isotope number 2 is to be used for mater al number 2, and so on.

The general form of the ASSIGN instruction is shown below

ASSIGN= zone1 mat 1 vol1, mat2 vol2, ..etc...;

where - zone1 is the holler:th name to be used for the first zone (the one specified with numeral, in the ZONE5 array). mat1, mat2. and so on are the hollerith names of the materials that will be present in this zone with, respectively, the volume fractions vol1, vol2, and so on.

Short form: $\quad$ ASSIGN= MATLS

This form specifies that material number 1 is to be assigned to zone number 1 , material number 2 to zone number 2 , and so on.

Note: The information entered in the MATLS= array is Written to the CCCC standard files NDXSRF and ZNATON. Information entered in the ASSIGN= array is written to the code dependent file ASGMAT 


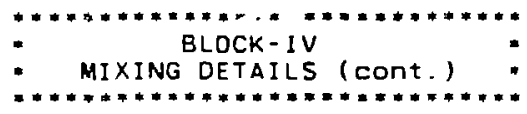

Additional Mixing Arrays

On the previous page, isotopes, materials, and zones were identified by their hollerith names. Optionally, they may be referred to by their ordinal number. Thus, 2 for an isotope name would call for the second isotope on the library.

THE HOLLERITH NANE FORM IS HIGHLY RECOMMENDED. It provides the most straight forward, wost understandable form. If the hollerith name form is used, the input arrays relow are unneeded.

Using the hollerith name form in one array and the numeric name form in another arrav is particularly discouraged. However. should one wish to use the tumeric form $n$ the MATLS= and/or ASSIGN= arrays, and then subsequently as ciate hollerith names with the ordinal numbers, one can use the following arrays to do so. This situation could arise. if for some reason, one wanted to use material numbers in the MATLS= array, but use hollerith material names in the ASSIGN = array.

MATNAM [MT ]

Hollerith material names for Materials. Used only if $\{$ optional\} the mat 1 name used in the MATLS= array was integer. First entry in MATNAM array is the hollerith name for Material number 1 . Eecond entry is the nollerith name for Material number 2, etc.

ZONNAM [NZONE] Hol lerith zone names for Zones. Used only if the zone \{optiona 1$\}$ name entry in the ASSIGN= array was integer. First entry in the ZONNAM= array is the hollerith name for zone number 1, second entry is the hollerith name for zone number 2, etc.

Concentration Searches

Concentration searches are not presently implemented in TWOHEX so the mixing array: pertaining to the search mentioned in the ONEDANT manual should be ignored. 


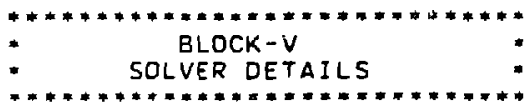

Name

Comments

-.....

Comments

IEVT

Calculation type: $0 / 1=$ homogeneous source/k eff

ISCT

Legendre order of scatiering

ITH

$0 / 1=$ direct/adjoint calculation

EPS I

OITM

Convergance precision (default $=0.0001$ )

Maximum no. of outer iterations (defaul $t=20$ )

ITLIM

Number of seconds time limit (default=unlimited)

FLUXP

$0 / 1 / 2=$ no/isotropic/

Final flux print

XSECTP

F I SSRP

SOURCP

a 11 momerits

$0 / 1 / 2=$ no/mixed/a11

$0 / 1=$ no/yes

Cross-section print

$0 / 1 / 2 / 3=$ no/unnormalized/

Fission rate print

normal ized/poth

Source print

Note on convergence criteria:

Note............................

For a k-effective calculation, an inner iteration sequence for a given group is terminated when the maximum scalar flux error is reduced to .04 times its value for the first inner iteration in the sequence. Tre outer iteration is terminated when the ratio of fission sources from outer to outer is within EPSi of unity and the naximum pointwise fission source error is less than 5 times EPSI. A source plus fission calculation must meet the same convergence criteria as a k-effective calculation. In an inhomogeneous problem the maximum scalar flux error must be less than EPSI for the problem to terminate. 


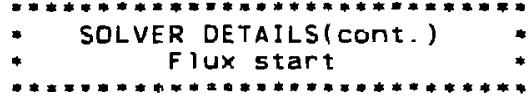

Name

Comments

Name.... -...-...-- comments

INF LUX

O/ 1 no/yes Read flux start from the RTFLUX file.

Note: There presently is no card input fl_. guess available. 


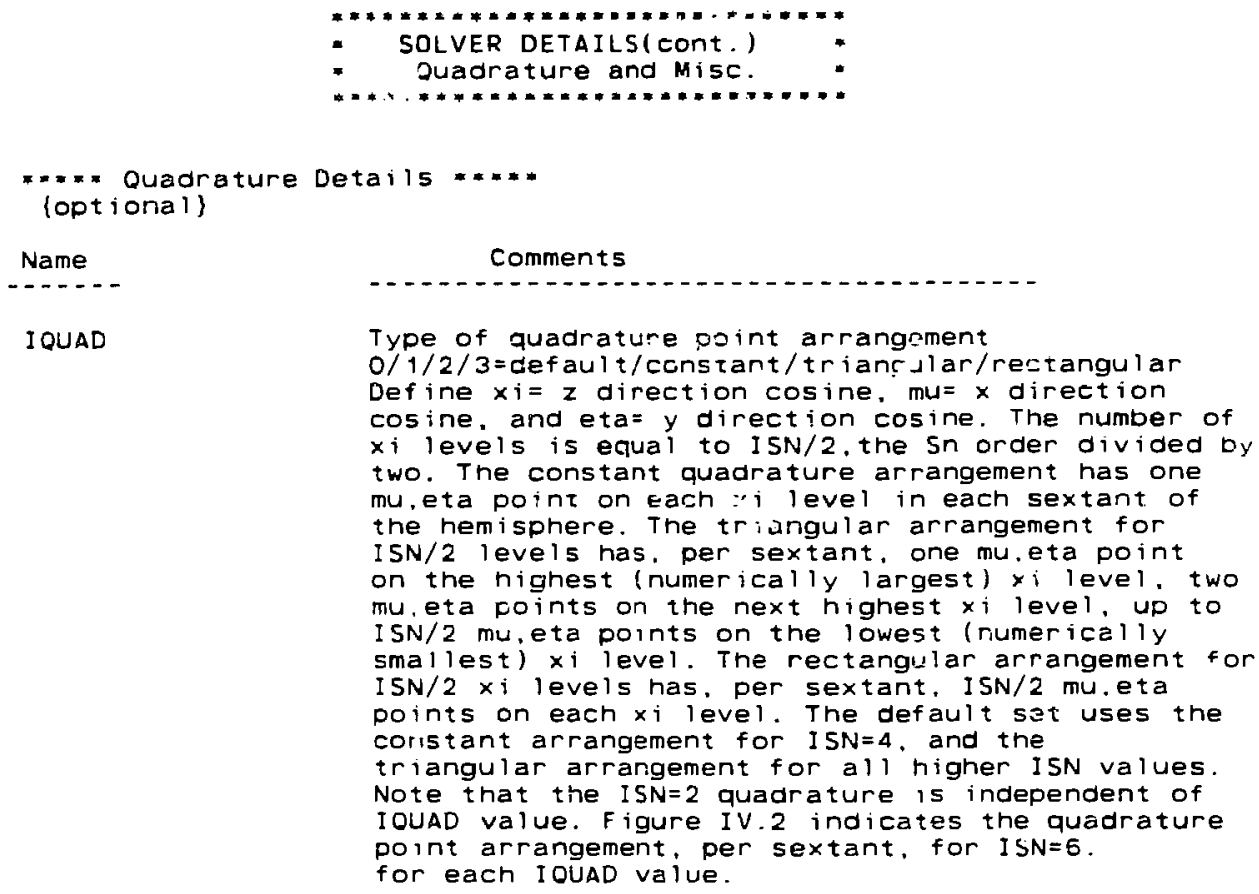

NORM

Normalize the fission source rate to this value when IEVT.GE. 1 or normal ize the inhomogeneous source rate to this value when IEVT.LT. 1 . NORM=O means no normalization. (Integral of source rate over all angle. space. and energy = NORM).

BHGT

Buckling height to use to correct for leakage. Units are centimeters.

CHI [NGROUP; M]

Fission fraction borm into each group. Enter by zone up to $M$ zones. Succeeding zones $(i . e$. zones $M+1$ through NZONE) will use the CHI values from zone $M$.

DENX [IT] and/or
DENY [ UT]

Density factor for the fine $x$-mesh (default $t=1)$. Density factor for the fine $y$-mesh (default=1)

Note: The full two-dimensional density factor, DEN (i,j), at mesh interval $(1, j)$ is computed as follows:

$\operatorname{DEN}(i, j)=\operatorname{DENX}(i) * \operatorname{DENY}(j)$ 


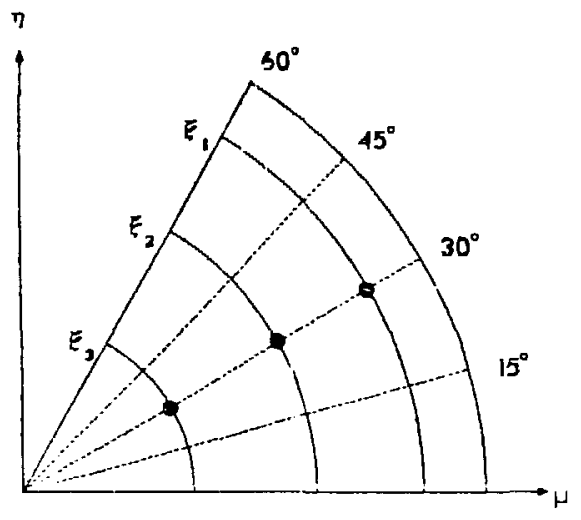

Figure IV.2a. Constent arrangement.

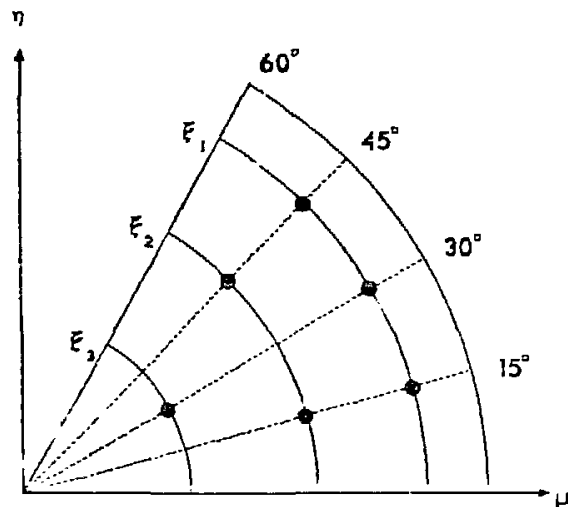

Figure iV.2b. Triangular arrangement.

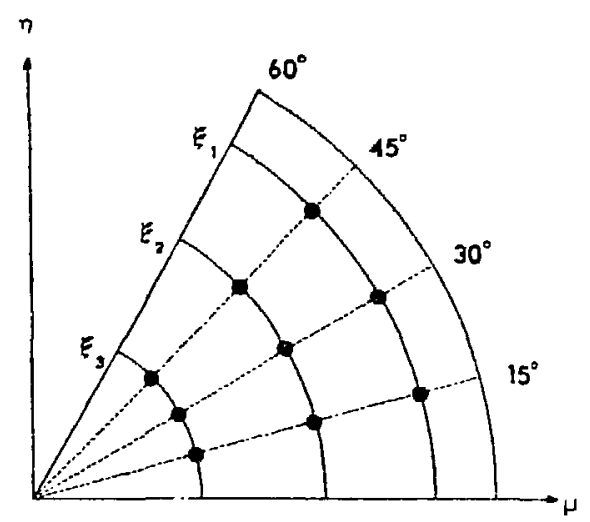

Figure IV.2c. Rectangular arrangement.

Figure IV.2. Possible quadralure arrangements. 

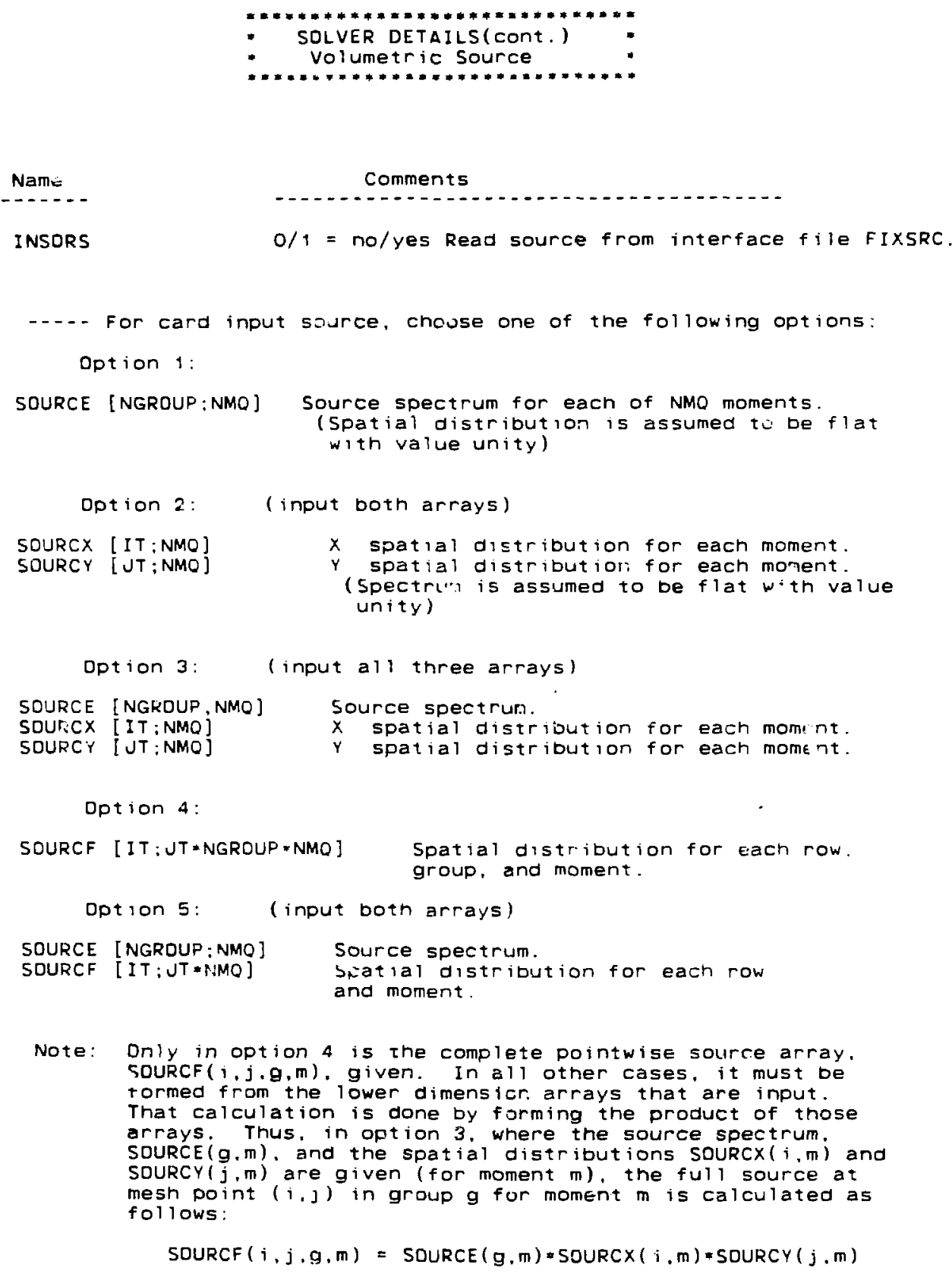

Dption 2: (input both arrays)

SOURCX [IT : NMO] SOURCY [UT;NMO]

$X$ spatial distribution for each moment.

Y spatial distributiori for each moment.

(spectri"l is assumed to be flat with value unity)

Option 3: (input all three arrays)

$\begin{array}{ll}\text { SOURCE [NGROUP,NMO] } & \text { Source spectrum. } \\ \text { SOURCX [IT;NMQ] } & X \text { spatial distribution for each mom } n t . \\ \text { SOURCY [UT;NMO] } & y \text { spatialdistribution for each moment. }\end{array}$

Dption 4:

SOURCF [IT:JT*NGROUP*NMQ] Spatial distribution for Each row. group, and moment.

Dotion 5: (input both arrays)

SOURCE [NGRDUP:NMO] SOurce spectrum.

SDURCF [IT:UT*N.MQ] SRatial distribution for each row and moment.

Note: Drly in option 4 is the complete pointwise source array. SOURCF $(i, j, g, m)$, given. In all other cases, it must be tormed from the lower dimensicr, arrays that are input. That calculation is done by forming the product of those arrays. Thus, in option 3, where the source spectrum. SDURCE $(\mathrm{g}, \mathrm{m})$. and the spatial distributions $\operatorname{SOURCX}(i, m)$ and SDURCY $(j, m)$ are given (for moment $m$ ), the full source at mesh point $(i, j)$ in group $g$ for moment $m$ is calculated as follows:

$\operatorname{SOURCF}(i, j, g, m)=\operatorname{SOURCE}(g, m) * \operatorname{SOURCX}(i, m) * \operatorname{SOURCY}(j, m)$ 


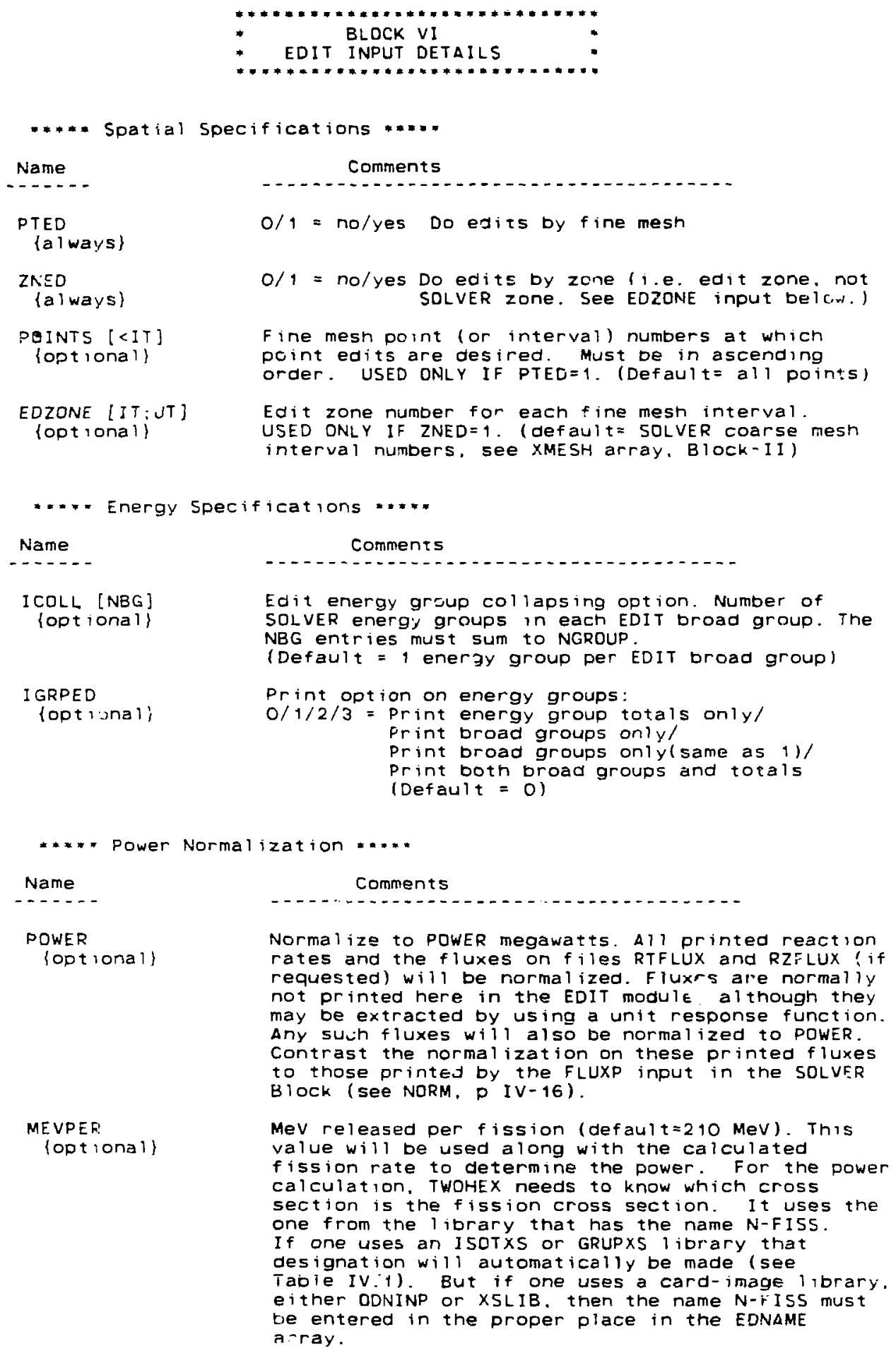

Normalize to POWER megawatts. All printed reaction rates and the fluxes on files RTFLUX and RZFLUX i if requested) will be normal ized. Fluxrs are normaliy not printed here in the EDIT module although they may be extracted by using a unit response function. Any sulh fluxes will also be normalized to POWER. Contrast the normalization on these printed fluxes to those printed by the FLUXP input in the SOLVER Block (see NDRM, p IV-16).

MeV released per fission (default $=210 \mathrm{MeV}$ ). This value will be used along with the calculated fission rate to determine the power. For the power calculation. TWOHEX needs to know which cross section is the fission cross section. It uses the one from the library that has the name N-FISS. If one uses an ISOTXS or GRUPXS library that designation will automatically be made (see Tabie IV. 1 ). But if one uses a card-image library. either ODNINP or XSLIB. then the name N-i ISS must be entered in the proper place in the EDNAME a-ray. 


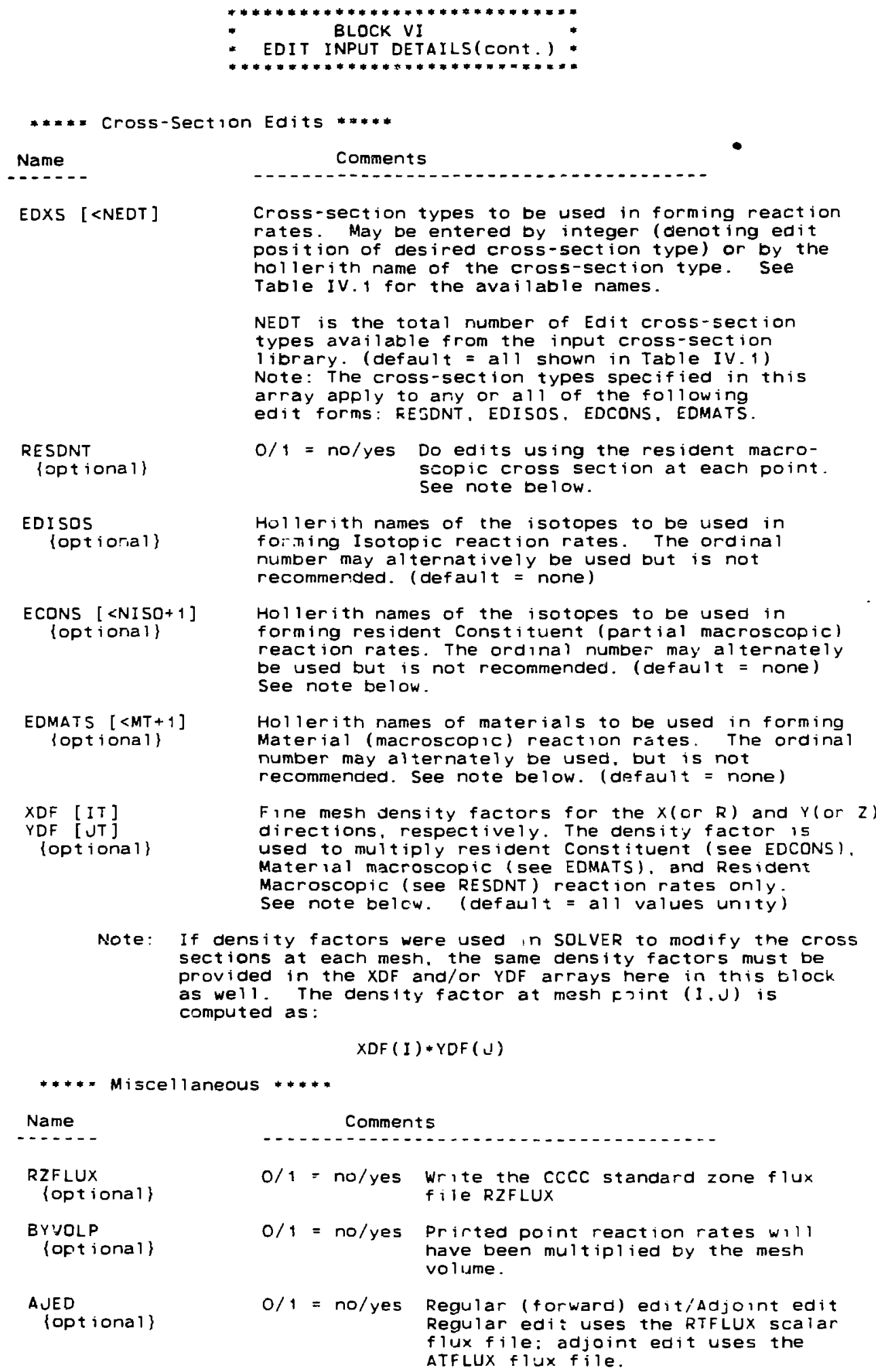




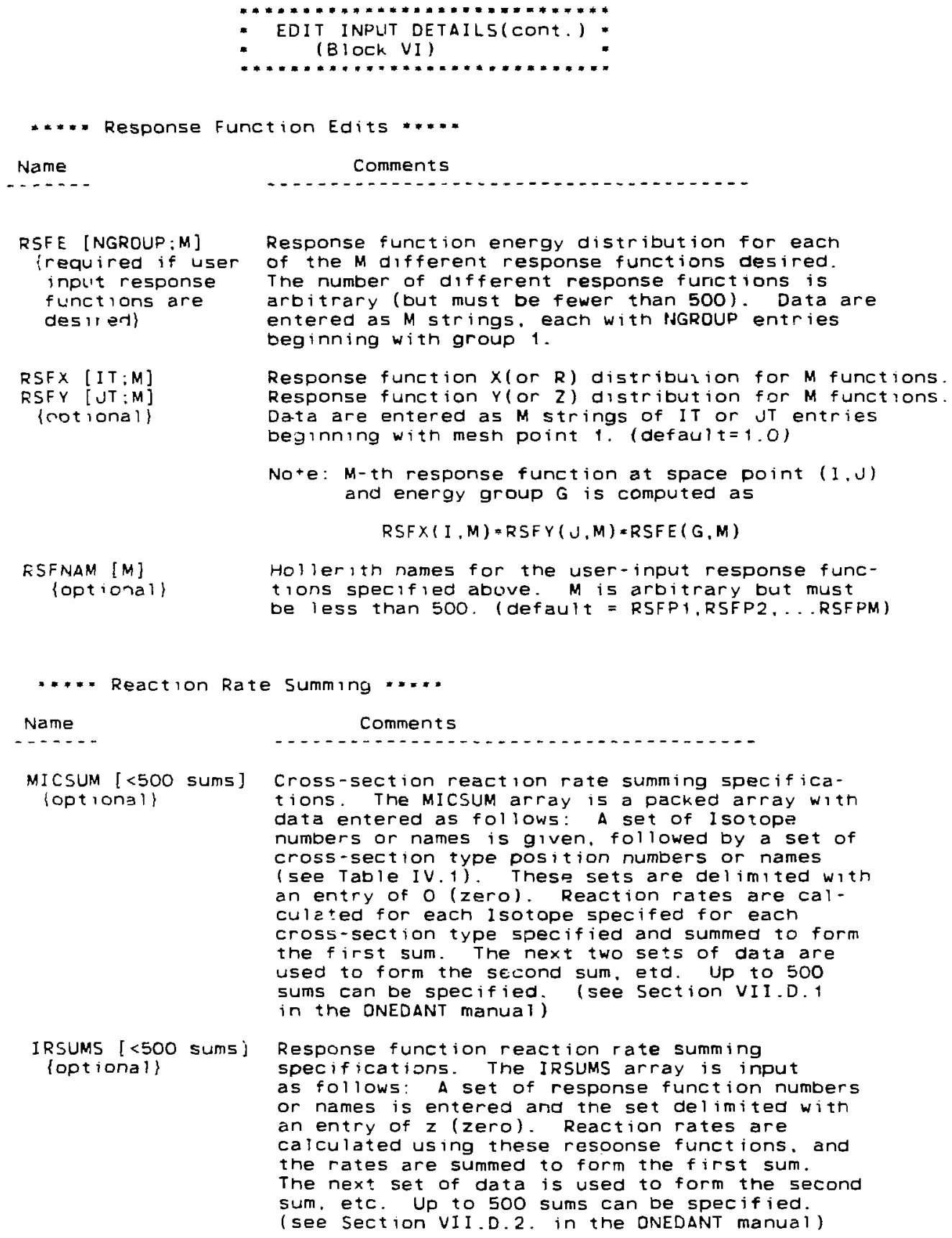




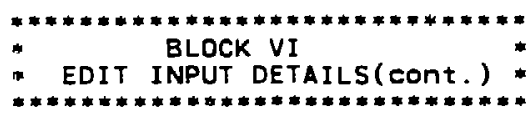

TABLE IV. 1

EDIT CROSS-SECTION TYPES BY POSITION AND NAME

\begin{tabular}{|c|c|c|}
\hline \multicolumn{3}{|c|}{$\begin{array}{l}\text { CROSS-SECTION INPUT } \\
\text { VIA I SOIXS/GRUPXS }\end{array}$} \\
\hline ype & $\begin{array}{l}\text { EDIT } \\
\text { osition }\end{array}$ & Name ( \\
\hline $\begin{array}{l}\text { chi } \\
\text { nu-fisston } \\
\text { total } \\
\text { absorption } \\
(n, p) \\
(n, d) \\
(n, t) \\
(n, a 1 p h a) \\
(n, 2 n) \\
(n, g a m m a) \\
\text { fission } \\
\text { transport }\end{array}$ & $\begin{array}{r}1 \\
2 \\
3 \\
4 \\
5 \\
6 \\
7 \\
8 \\
9 \\
10 \\
11 \\
12\end{array}$ & $\begin{array}{l}\text { CHI . . } \\
\text { NUSIGF } \\
\text { TOTAL. } \\
\text { ABS... } \\
\text { N-PROT } \\
\text { N-DEUT } \\
N \text {-TRIT } \\
\text { N-ALPH } \\
\text { N-2N. } \\
\text { N-GAMM } \\
\text { N-FISS } \\
\text { TRNSPT }\end{array}$ \\
\hline
\end{tabular}

CROSS-SECTION INPUT

VIA BCD CARD-IMAGES

(1) EDIT

Type Position Name (a)

not used 1 CHI...

nu-fission 2 NUSIGF

total 3 TOTAL

absorption 4 ABS...

1 (b) 5 EDIT1. (c)

2 (b) 6 EDIT2. (c)

3 (b) 7 EDIT3. (c)

$N=I H T-3 \quad 4+N \quad E D I T N . \quad$ (c)

Notes:

a. Names are six character hollerith. A perlod within a name denotes a blank.

b. Denotes position (row) in the cross-section table. All cross sections in rows (positions) 1 through IHT-3 in the cross-section Tibrary are EDIT cross sections chosen by the user.

c. These are the default names that may be overridden with the useroption names in the EDNAME array of Block III. 
APPENDIX A

INTERFACE FILE SPECIFICATIONS

The user 15 referred to the ONEDANT manual (Ref. 2 ) for a description of the code-dependent interface files. Those files are identical to the ones used here in TWOHEX.

The standard interface files used by TwDHEX are those defined by the Committee on Computer Code coordination and are described in reference 1 . 
On the following page is; a small but complete sample problem input. It 1 s a two group calculation of the eigenvalue of a sodium cooled fast reactor. On a CRAY-15. a converged eigenvalue of 1.01435 is calculated in 10 outer iterations.

The geometric mcjel contains two zones, a core zone composed of two rows of fuel subassenblies surrounding a central fuel subassembly and a reflector zone corsisting of one row of reflector assemblies surrounding the core zone. Each subassembly is modeled with 6 triangles. Leakage in the axial dimension is approximated with a buckling consistent with a core height of ninety centimeters.

Po cross sections for each isotope are entered in the input stream after Block-III. These isotopes are subsequently mixed to form the materials STEEL. FUEL. AND SODIUM. These materials are then assigned with appropriate volume fractions to the CORE and REFLECTOR zones.

Irl the edit input, the code is asked to give reaction rate totals for each triangle. The reaction rates desired are the default ones. that 15. CHI. NUSIGF. TOTAL. ABS, and ENIT t (EDIT1 is the default name for the first position in the card-image library).

Note the use of comments (using the slash, /) to organize and desc: ibe the input.

A note of warning about modeling is in order here. This sample problem utilizes a sixth core model for which there are "vacuum" boundary conditions on the top and $r i g h t$ faces. These boundaries are really non-reentrant boundaries (i.e. the flux passing outward through these boundaries is lost and does not reenter a boundary anywhere else). Note that the sample model contains extra void triangles around the exterior of the reflector. This is to provids a streaming path within the model for flux leaving the reflector that truly can reenter another portion of the reflector. Removal of these extra void triangles will cause the eigenvalue and fluxes to be slightly lower 
200

SAMPLE PROBLEM FOR TWOHEX USER'S GUIDE

STANDARD $K$ CALCULATION, ALL INPUT BY MEANS OF CARD-IMAGES

GEOMETRY - SIXTH CDRE WITH PERPENDICULAR BUCKLING

CROSS SECTIONS - 2 GROUP, ISOTROPIC SCATTER

ISOTDPE DATA ON CARDS: LDS ALAMOS (DTF) FORMAT

MIXING

- ISOTDPES MIXED TO MAKE MATERIALS NAMED STEEL. FUEL, AND SODIUM

- MATERIALS ASSIGNED TO MAKE zONES NAMED CORE AND REFLECTOR

SOLVER - CARD TNPUT SUPPLIED

EDITS - POINT EDITS FOR RESIDENT MATERIALS

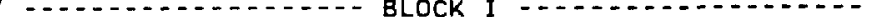

IGEOM=9, NGROUP=2, ISN=4, NISO=7, $M T=3, N Z O N E=2, I T=12, J T=6, T$

/

DOMAIN $=5 I \times T H, \quad H E I G H T=10.0$.

ZONES = 7R1 3R2 FO: 6R1 3R2 FO: 5R1 3R2 FO:/ ZONE NOS. FOR BANDS 1.2,3 1 SR2 FO; $3 R 2$ FO; FO; $T$ / ZONE NOS. FOR BANDS $4,5.6$

/

$L I B=$ ODNINP

MAXDRD $=0 \quad$ IHM $=6 \quad$ IHT $=4 \quad$ IHS $=5 \quad$ IFIDO $=0 \quad$ ITITL $=$ i

NAMES = "0-16" "NA-23" FE CR NI "PIJ-239" "U-238"

'

**\#* SINCE LIB=ODNINP. THE CROSS SECTIDN LIBRARY IN CARD-IMAGES

WILL REGIN IMMEDIATELY FOLLOWING THE BLDCK III TERMINAL "T".

NOTE THAT A TITLE CARD PRECEDES EACH CROSS-SECTION

BLOCK (SINCE ITITL=1).

$T$

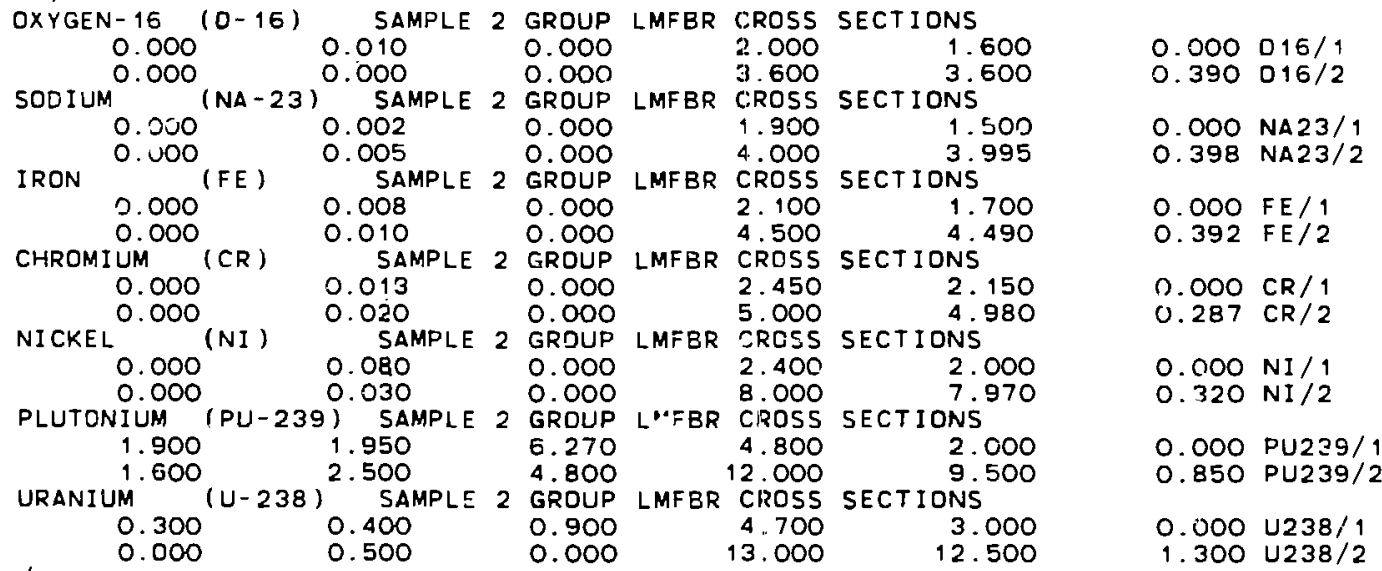

$/ \% * * * *$ END OF CROSS-SECTION DATA *******

/... NOTE THat THERE IS No TERMINAL " $T:$ SINCE THE CROSS SECTIONS ARE

IN lOS ALAMOS (DTF) FDRMAT (IFIDO=0) ***

STEEL FE OSLCK IV (MIXING) -

FUEL "PU-239".0081, "U-238".0125 "D-16".0412;

SDDIUM "NA-23"

ASSIGN= CORE FUEL .35, SODIUM. 4, STEEL . 25:

REFLEC SODIUM. 7 , STEEL .3, STEEL . $25 . T$

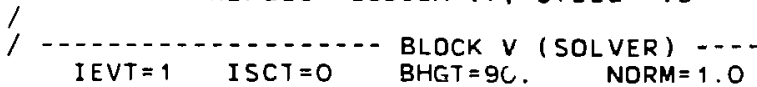

FLUXP $=1 \quad$ XSECTP=2 FISSRP $=1 \quad$ CHI $=0.6 .0 .4 ; 0.7 .0 .3 \quad i$

/

PTED $=1$, RESDNT $=1, T /$ POINT EDIT FOR RESIDENT MATERIALS 
The TWOHEX code is presently maintained at the Central Computing Facility (CCF) ar the Los Alamos National Laboratory. The following paragraphs show how to access and execute the code at that facility under the CTSS systems. No LTSS version is presently being maintained.

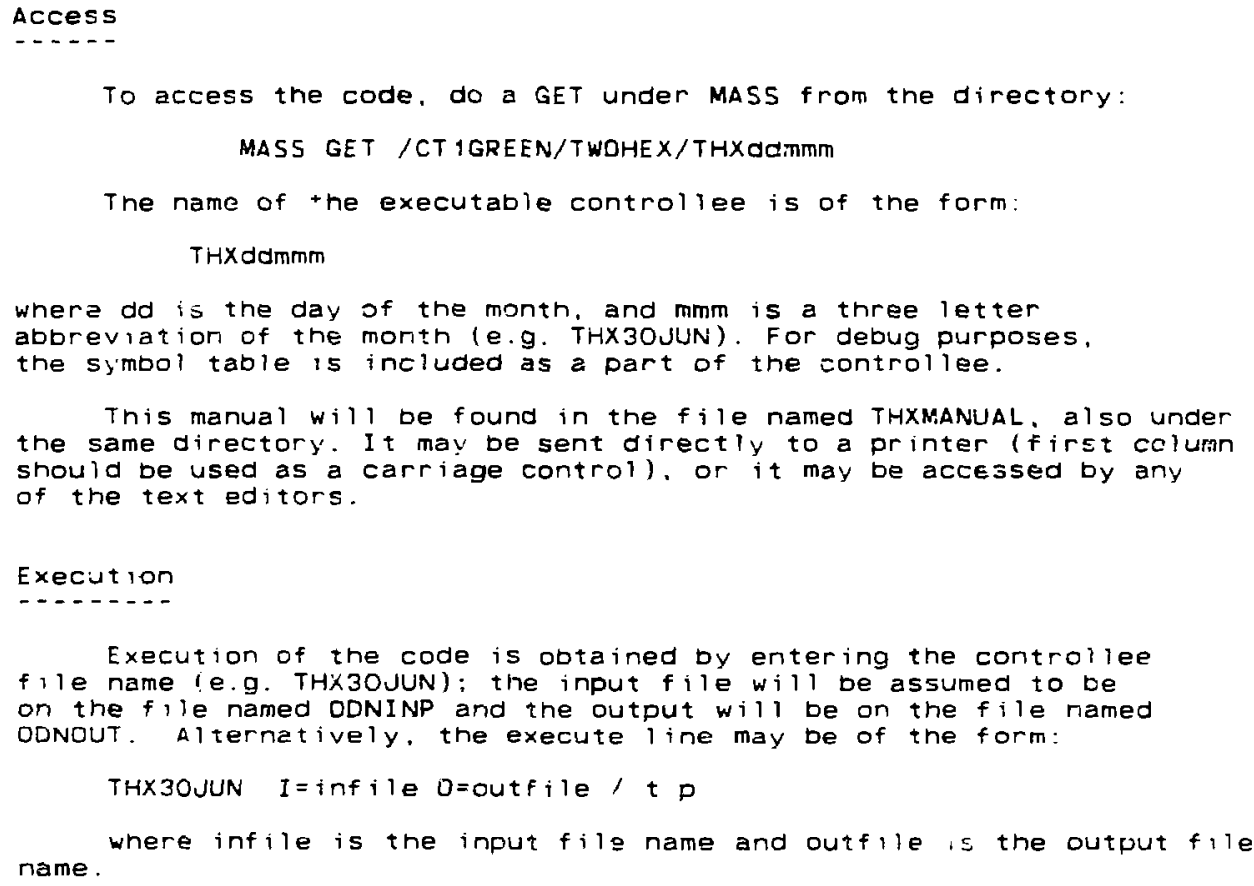




\section{REFERENCES}

1. R. D. D'Dell. "Standard Interface Files and Procedures for Reactor Physics Codes, Version IV." Los Alamos Scientific Laboratory report LA-6941-MS (September 1977).

2. R. D. O'Dell, F. W. Brinkley, and D. R. Marr. "User's Manual for ONEDANT: A Code Package for One-Dimensional, DiffusionAccelerated. Neutral-Particle Transport." Los Alamos National Laboratory report LA-9184-M (February 1982).

3. W. F. Walters, "The TLC Scheme for Numerical Solution of the Transport Equation on Equilateral Triangular Meshes." Proc. Am. Nucl. Soc. Top. Meeting on Advances in Reactor Computations. Selt Lake City, Utah. March 28-31, 1983, Vo . 1, pp 151-165.

4. D. R. Ferguson and K. L. Derstine, "Optimized Iteration Strategies and Data Management Considerations for Fast Reactor Finite Difference Diffusion Theory Codes. "Nucl. Sci. Eng. 64. 593 (1977).

5. K. L. Derstine, "DIF3D: A Code to Solve One-.Two-, and ThreeDimensional Finite-Difference Diffusion Theory Problems." Argonne National Laboratory report ANL-B2-64 (Apr 11 1934).

6. W. W. Engle. Ur.. "A USER'S MLAUAL FOR ANISN, A DNe Dimensional Discrete Ordinates Transport Code With Anisotropic Scattering," Union Carbide report K-1693 (March 1967).

7. W. A. Rhoades and $F$. R. Mynatt, "THE DOT III TWO-DIMENSIDNAL DISCRETE ORDINATES TRANSPORT CODE." Dak Ridge National Labcratory report ORNL-TM-4280 (September 1973). 